Old Dominion University

ODU Digital Commons

\title{
Quantitative Analysis of X-ray Fluorescence Absorption and Emission for Thickness Determination of ALD-Grown Metal and Oxide Nanoscaled Films
}

Tarek M. Abdel-Fattah

Alex Wixtrom

Larry Arias

Kai Zhang

Old Dominion University, kzhang@odu.edu

Helmut Baumgart

Old Dominion University, hbaumgar@odu.edu

Follow this and additional works at: https://digitalcommons.odu.edu/ece_fac_pubs

Part of the Electronic Devices and Semiconductor Manufacturing Commons

\section{Original Publication Citation}

Abdel-Fattah, T. M., Wixtrom, A., Arias, L., Zhang, K., \& Baumgart, H. (2017). Quantitative analysis of X-ray fluorescence absorption and emission for thickness determination of ALD-grown metal and oxide nanoscaled films. Journal of Nanoscience and Nanotechnology, 17(8), 5745-5750. doi:10.1166/ jnn.2017.13827

This Article is brought to you for free and open access by the Electrical \& Computer Engineering at ODU Digital Commons. It has been accepted for inclusion in Electrical \& Computer Engineering Faculty Publications by an authorized administrator of ODU Digital Commons. For more information, please contact digitalcommons@odu.edu. 


\title{
Quantitative Analysis of X-ray Fluorescence Absorption and Emission for Thickness Determination of ALD-Grown Metal and Oxide Nanoscaled Films
}

\author{
Tarek M. Abdel-Fattah ${ }^{1, *}$, Alex Wixtrom ${ }^{1}$, Larry Arias $^{2}$, Kai Zhang ${ }^{3}$, and Helmut Baumgart ${ }^{3}$ \\ ${ }^{1}$ Applied Research Center Thomas Jefferson National Accelerator Facility and Department of Molecular Biology and Chemistry at \\ Christopher Newport University, Newport News, Virginia 23606, United States \\ ${ }^{2}$ Bruker AXS, Inc., Madison, WI, 53711, United States \\ ${ }^{3}$ ODU-Applied Research Center, Newport News, VA, and Department of Electrical Engineering, Old Dominion University, \\ Norfolk, Virginia 23529, United States
}

\begin{abstract}
This study describes the use of X-ray fluorescence spectroscopy (XRF) to determine the thickness of nanoscaled thin films of insulating oxides such as $\mathrm{Al}_{2} \mathrm{O}_{3}, \mathrm{HfO}_{2}$, and $\mathrm{ZrO}_{2}$, semiconducting oxides such as $\mathrm{TiO}_{2}, \mathrm{ZnO}$, and metals like $\mathrm{Pt}$, on silicon substrates synthesized by atomic layer deposition (ALD) technology. XRF thickness measurements were compared with the predicted layer thickness based on calculations from known ALD growth rates for each metal or metal oxide films. The ALD growth rates have been calibrated with TEM cross-sectional measurements of the resulting film thickness. The results showed good agreement between the two methods, indicating the XRF technique was successful. Quantitative XRF spectroscopy employing XRF absorption and emission line analysis has been demonstrated to be a powerful non-destructive tool for thickness determination of deposited high- $k$ transition metal oxides and other technologically important nano-scaled thin films like Pt and other metal contacts and reveals new untapped application potential for XRF.
\end{abstract}

Keywords: Non-Destructive, X-ray Fluorescence Spectroscopy, XRF, Atomic Layer Deposition, ALD, Nanoscale, Thin Films, Thickness Determination.

\section{INTRODUCTION}

$\mathrm{X}$-ray fluorescence (XRF) spectroscopy is a powerful yet flexible quantitative analysis technique. XRF has been used to determine elemental compositions of many minerals, rocks, alloys, glasses, cements, polymers and thin films of technological importance. One of the key benefits of XRF analysis is the non-destructive nature of the technique, a factor that the semiconductor industry leverages to enable in-line XRF analysis for quality control during the manufacturing process of microelectronic devices such as dynamic random access memories (DRAMs), microprocessors, and application specific integrated circuits (ASICs). ${ }^{1}$ In addition to elemental composition analysis, XRF is a useful analytical technique for determination of film thickness or density. ${ }^{2-4}$

While XRF is frequently employed in a range of analytical applications, ${ }^{3,5-8}$ the fundamentals of the principles

${ }^{*}$ Author to whom correspondence should be addressed. enabling these applications are often overlooked. During $\mathrm{XRF}$ analysis, a sample is irradiated with a high-energy $\mathrm{X}$-ray photon flux resulting in electrons gaining sufficient energy for being forcibly ejected from the atoms' inner shell struck by the X-ray beam. This creates a 'hole' in one or more atomic inner shells of the analyte species, thus converting the atom(s) into unstable ions: For the affected atom(s) to return to a more stable state, the holes (also known as "initial vacancies" or missing electrons) created by the X-ray bombardment in the inner shells must be filled by electrons transferred from the outer orbitals. This electron transition from higher-energy outer shells to lower-energy inner shells results in the emission of secondary X-ray photons (fluorescence). The energy of the emission is dependent on both the outer shell the transferred electron originally occupied (i.e., $\mathrm{K}, \mathrm{L}, \mathrm{M}$-shells) as well as the type of atom or chemical element. Each element produces a unique emission spectrum, and the intensity of the emission lines relates to the concentration of 
that element. ${ }^{9,10}$ More details about the history of XRF as an analytical technique and the mathematical principles that govern thickness and density determination have been well documented in previous studies. ${ }^{2-4,8,10-14}$

In this study, the application of XRF as a nondestructive method for the determination of layer thickness and elemental composition of deposited nanoscale thin films of high- $k$ transition metal oxides and pure metals on silicon substrates was evaluated. These measurements were compared with calculated predictions for layer thickness based on atomic layer deposition (ALD)-calibrated growth rates, in addition to using destructive cross-section analysis via field emission scanning electron microscopy (FE-SEM) and transmission electron microscopy (TEM). XRF analysis was shown to accurately and reliably determine the film thickness non-destructively for all of the samples evaluated, indicating the value of the use of XRF analysis as a rapid tool for thickness determination of nanoscale metal and metal oxide thin films.

\section{EXPERIMENTAL DETAILS}

Since the advent of nanotechnology, Atomic Layer Deposition (ALD) thin film deposition technology has experienced increased interest in research and development and the semiconductor electronics industry. ALD provides unique features such as precise control of thin films with atomic resolution, high uniformity, good conformality, surface saturating property, self-limited reactions and conformal coverage of complex high aspect ratio surface morphologies that extend even to negative slopes and cavities. The final resulting film thickness in an ALD deposition is linearly dependent on the number of ALD deposition cycles. For these reasons, ALD was used in this study to prepare nanoscale thin films of the following metal oxides $\mathrm{Al}_{2} \mathrm{O}_{3}, \mathrm{HfO}_{2}, \mathrm{TiO}_{2}, \mathrm{ZnO}, \mathrm{ZrO}_{2}$ and a pure Pt metal film on silicon substrates. The ALD films were deposited on native oxide covered (100) oriented $\mathrm{Si}$ substrates of four inch diameter by a thermal ALD synthesis process in a Savannah 100 cross-flow reactor from Ultratech/Cambridge Nanotech. Generally, an ALD thin film synthesis process consists of a series of two alternate chemical precursor pulse and purge steps. Each ALD cycle is composed of exposing the substrate in the ALD reaction chamber to the first chemical precursor, followed by purging the chamber with inert gas (ex: $\mathrm{Ar}, \mathrm{N}_{2}$ ), and finally reacting precursor 2 with precursor 1 in order to synthesize the desired thin film material. ALD deposition cycles for chemical precursor 1 and subsequent precursor 2 are separated by $\mathrm{N}_{2}$ purge steps with inert gas to remove unreacted precursor and by-products from the reactor between precursor pulses through evacuation. In our experiments, $20 \mathrm{sccm} \mathrm{N}_{2}$ was used as a carrier gas to transport the chemical precursors into the ALD reaction chamber. The chamber base pressure was kept at 30 mTorr. The chemical ALD precursors utilized for this work and the ALD film
Table I. Chemical precursors, deposition temperatures, and growth rate for ALD process.

\begin{tabular}{lcccc}
\hline Materials & $\begin{array}{c}\text { Deposition } \\
\text { temp. } \\
\left({ }^{\circ} \mathrm{C}\right)\end{array}$ & Precursor 1 & $\begin{array}{c}\text { Precursor } \\
2\end{array}$ & $\begin{array}{c}\text { Growth } \\
\text { rate } \\
(\AA / \text { cycle })\end{array}$ \\
\hline $\mathrm{Al}_{2} \mathrm{O}_{3}$ & 300 & Trimethyl aluminum & $\begin{array}{c}\mathrm{H}_{2} \mathrm{O} \\
\text { vapor }\end{array}$ & 1 \\
$\mathrm{HfO}_{2}$ & 250 & Tetrakis(dimethylamido)hafnium & $\begin{array}{c}\mathrm{H}_{2} \mathrm{O} \\
\text { vapor }\end{array}$ & 1 \\
$\mathrm{Pt}$ & 300 & (Trimethyl)methylcyclopentadienyl & $\begin{array}{c}\text { Oxygen } \\
\text { platinum }\end{array}$ & 0.5 \\
$\mathrm{TiO}_{2}$ & 250 & Titanium isopropoxide & $\begin{array}{c}\mathrm{H}_{2} \mathrm{O} \\
\text { vapor }\end{array}$ & $0.3-0.4$ \\
$\mathrm{ZnO}$ & 150 & Diethyl zinc & $\begin{array}{c}\mathrm{H}_{2} \mathrm{O} \\
\text { vapor }\end{array}$ & 2.3 \\
$\mathrm{ZrO}_{2}$ & 250 & Tetrakis(dimethylamido)zirconium & $\begin{array}{c}\mathrm{H}_{2} \mathrm{O} \\
\text { vapor }\end{array}$ & 1 \\
& & & & \\
\hline
\end{tabular}

deposition temperatures are summarized in Table I, along with the experimentally determined growth rate of each of the investigated thin ALD films.

Typically the ALD precursor 1 consists of a complex organo-metallic compound, and precursor 2 serves as the oxidizing agent to sever the ligands from the organometallic compound, and to finally synthesize the transition metal oxide by an oxidation reaction. The DI $\mathrm{H}_{2} \mathrm{O}$ vapor of ALD precursor 2 acted as oxidizing agent to complete the chemical reaction for the synthesis of all ALD metal oxide films, with the exception of the Pt synthesis. ALD film depositions were carried out over the reactor temperature range of $150{ }^{\circ} \mathrm{C}$ to $320^{\circ} \mathrm{C}$ in order to establish the optimum ALD process window, which had to be experimentally determined for each individual ALD synthesized compound. For platinum metal films we investigated the synthesis of ALD Pt thin films using the metal organic compound (methylcyclopentadienyl) trimethylplatinum $\left(\mathrm{MeCpPtMe}_{3}\right)$ and oxygen as the chemical ALD precursors. The metal organic compound $\mathrm{MeCpPtMe}_{3}$ was heated to $80^{\circ} \mathrm{C}$ in order to generate sufficient vapor pressure. For the experimental work the pulse time for the chemical precursors $\mathrm{MeCpPtMe}_{3}$ and oxygen was $1 \mathrm{~s}$ and $0.1 \mathrm{~s}$, respectively, to enter the ALD reaction chamber. The two precursor vapor pulses were separated by $5 \mathrm{~s}$ of $\mathrm{N}_{2}$ purging pump time.

For the synthesis of $\mathrm{Al}_{2} \mathrm{O}_{3}$ ALD films, we utilized trimethyl aluminum (TMA) as precursor 1 and de-ionized (DI) $\mathrm{H}_{2} \mathrm{O}$ vapor as the oxidizing agent at $300{ }^{\circ} \mathrm{C}$ ALD deposition temperature. For the transition metal $\mathrm{HfO}_{2}$ ALD films, we utilized tetrakis(dimethylamido)hafnium and DI $\mathrm{H}_{2} \mathrm{O}$ vapor at a deposition temperature of $250{ }^{\circ} \mathrm{C}$. The $\mathrm{ZrO}_{2}$ ALD films were synthesized with tetrakis(dimethylamido)zirconium and $\mathrm{DI} \mathrm{H}_{2} \mathrm{O}$ vapor at a deposition temperature of $250^{\circ} \mathrm{C}$. The lowest ALD deposition temperature was used for $\mathrm{ZnO}$ films, which were synthesized with diethyl zinc (DEZ) and DI $\mathrm{H}_{2} \mathrm{O}$ vapor at $150{ }^{\circ} \mathrm{C}$. Finally $\mathrm{ALD} \mathrm{TiO}_{2}$ was synthesized with titanium isopropoxide and $\mathrm{DI} \mathrm{H}_{2} \mathrm{O}$ vapor at $250^{\circ} \mathrm{C}$. Following ALD 
synthesis, the thin films were analyzed using a Bruker S4Pioneer X-ray fluorescence spectrometer to quantitatively determine the actual thickness of the deposited layers.

No special treatment of thin film samples was required to perform XRF analysis, and pure metals were utilized as standards. Counting times of 998 s (at peaks) and $200 \mathrm{~s}$ (at backgrounds) were used to obtain a good counting statistic error. The XRF analysis software used to determine thickness of thin film layers was MLQUANTG, which uses the density of metals as input parameters in order to estimate the thickness of films from the measured XRF spectra. For optically transparent transition metal oxide films, ellipsometry was also used to determine the thickness of the deposited layers, using a Woollam VASE model. Ellipsometry however, cannot be applied to opaque ALD metal films like Pt. Cross sectional transmission electron microscopy (TEM) and field emission scanning electron microscopy (FE-SEM) analysis of the thin films was performed using a JEOL TEM, and a Hitachi Model S-4700 FE-SEM.

\section{RESULTS AND DISCUSSION}

The thicknesses of thin, multi-layered ALD samples were analyzed in this study using XRF quantitative software (SPECTRAplus MLQuantG) based on fundamental parameters, and the results were compared to ellipsometry, FE-SEM and TEM cross-sectional microscopy imaging, and ALD growth-rate calculations. The MLQuantG program calculates the relative intensities that would be produced from an assumed composition and thickness of the layered sample using the Sherman Equation (equation S1, Supporting Information). ${ }^{15}$

The intensities measured from the layered sample are converted to relative intensities using a stored calibration from bulk samples. An iterative calculation is then used where the assumed composition and thickness of the layered sample are adjusted and new relative intensities are calculated until the theoretically calculated intensities match the measured intensities within a user adjustable tolerance. While earlier XRF software was only considered accurate enough to be considered semi-quantitative, ${ }^{16}$ improvements over the past two decades with more recent software have shown excellent agreement with alternative physical characterization methods for layer thickness determination (e.g., ellipsometry, allowing for true quantitative, even reference-free, layer thickness analysis). ${ }^{3,17}$ The fundamental parameter-based software used in this study utilized two different XRF-based methods to quantitatively determine layer thicknesses.

The first method detected the intensity of the radiation emitted by a given layer to directly calculate thickness, while the second method measured the reduction in intensity of the emission from the underlying layer (or substrate) directly beneath the layer of interest due to the absorption by the layer itself (Fig. 1). The matrix effects
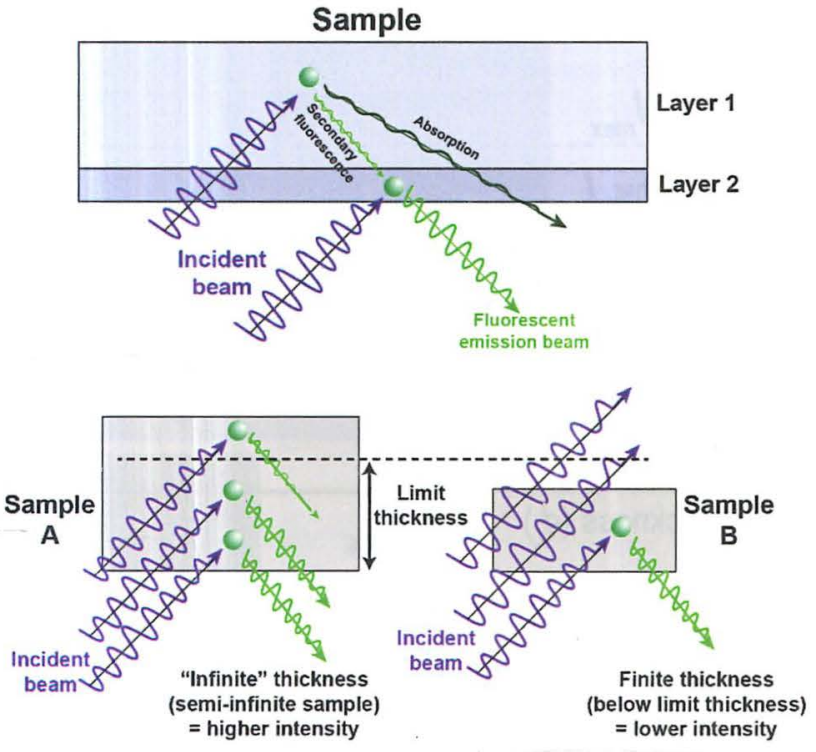

Figure 1. XRF sample analysis diagram demonstrating fluorescence emission lines and limit thickness.

of primary (incident beam from underlying layers) and secondary (fluorescent radiation from underlying layers) absorption, along with enhancement of the fluorescence of outer layers from the underlying layer(s) or substrate determine the intensity of the fluorescent emission beam, which is then used for thickness evaluation.

For a thin layer, provided the density and composition are uniform across the layer, the emission intensity increases with thickness, up to a point of maximum intensity $\left(I_{\max }\right)$ for "semi-infinite" thickness. Below the limit thickness, the intensity decreases (Fig. 1). The transition between a "semi-infinite" thickness and a finite thickness is defined as the limit thickness, which is calculated from the $d_{90 \%}$ thickness, the thickness at which the measured intensity is $90 \%$ of the maximum. This parameter, also known as the "90\% absorption path" or "saturation thickness," is dependent on density and chemical composition of the sample, along with the energy of the line (characteristic of the element being analyzed). Thus, the limit thickness for a sample will have differing limit thicknesses for each measured emission line. Of the two previously mentioned methods for determining layer thickness, if the emission of an element within a layer of interest is to be used, that layer must be below the limit thickness (or $d_{90 \%}$ ) to ensure the intensity is sufficient to provide an accurate measurement. For thicker samples, the absorption line emitted from an underlying layer, rather than the direct emission line from the layer of interest, is used to maintain accuracy of the measurement. This is due to the absorption-based method remaining accurate up to triple the $d_{90 \%}$ limit thickness, where $99.9 \%$ of the radiation is absorbed (1/1000th transmitted) by the layer of interest (Fig. 2). 

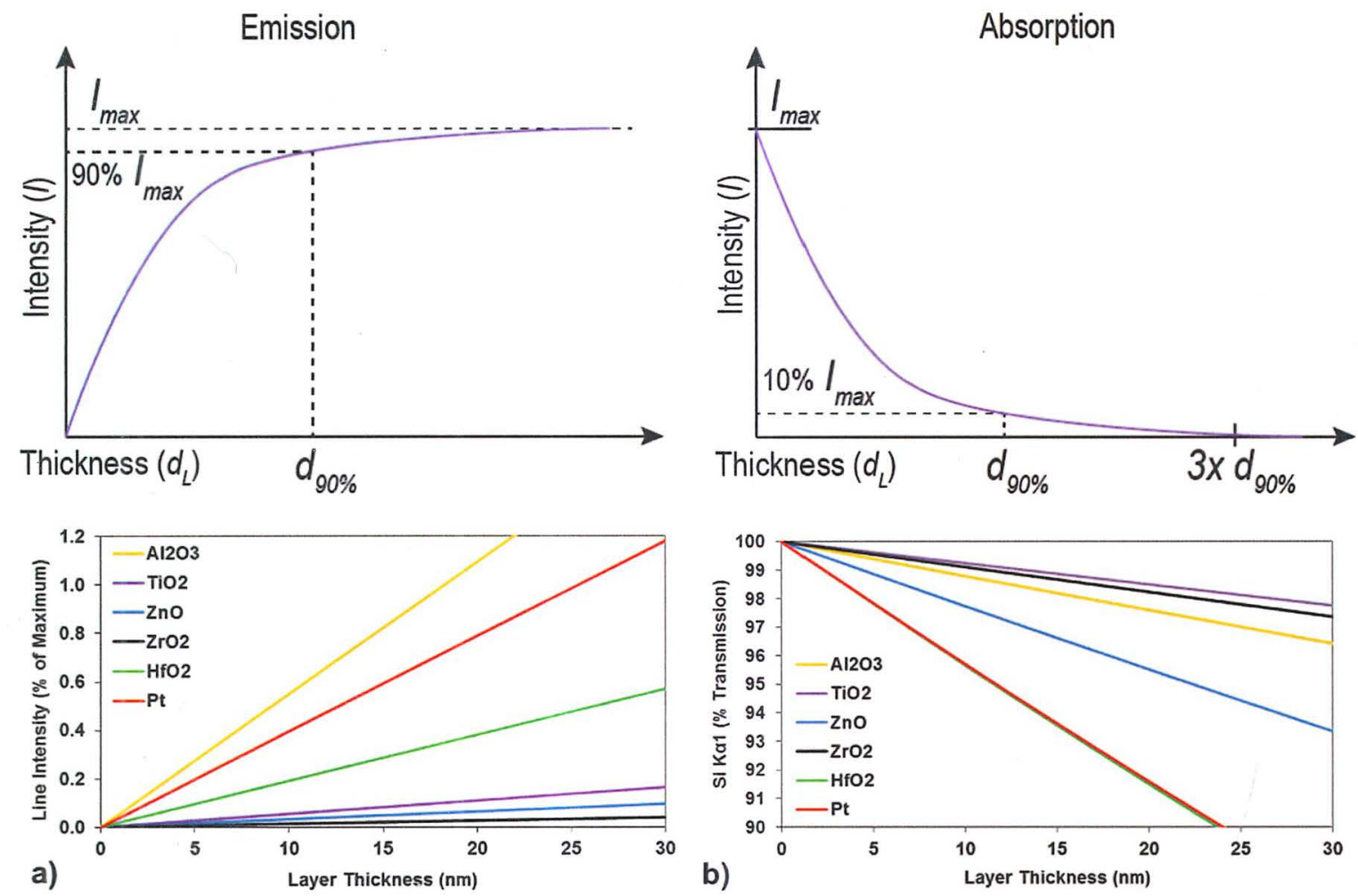

Figure 2. Illustration indicating how $d_{90 \%}$ is used for thickness determination for emission (a) and absorption (b) fluorescence lines.

The techniques described above relate to methods used to calculate the thicknesses of layers containing a single element, but the same process can be used for mixed composition layers, provided the aforementioned properties of uniform density and composition are consistent. Very little work exists employing these techniques for the analysis of these technologically important nano-scaled thin films.

In this study, we evaluated a variety of single-layer metal $(\mathrm{Pt})$ and insulating transition metal oxide $\left(\mathrm{Al}_{2} \mathrm{O}_{3}\right.$, $\mathrm{HfO}_{2}$, and $\mathrm{ZrO}_{2}$ ) thin films with high dielectric constant $k$ in addition to $n$-type electrically conductive metal oxides $\left(\mathrm{TiO}_{2}, \mathrm{ZnO}\right)$ films deposited on silicon substrates by ALD synthesis. The thickness of each sample was experimentally determined by XRF analysis, and these results were compared with data independently obtained from ellipsometry, cross-sectional TEM, and SEM imaging analysis from film cleavage sites. This data was then compared with the estimated thicknesses of the thin films calculated from the experimentally calibrated ALD growth rates in $\AA / A L D$ cycle, and the known number of ALD deposition cycles used to grow the measured film thickness. The linearity of the ellipsometer-determined thickness and ALD growth rate for $\mathrm{HfO}_{2}$ and $\mathrm{Al}_{2} \mathrm{O}_{3}$ can be seen in Figure 3. This data was used to calibrate the film thickness obtained per ALD cycle, allowing for predicted calculations of layer thickness control based on a known number of ALD deposition cycles.

TEM cross-sectional images confirmed the final ALD film thickness after a set number of ALD deposition cycles, as seen in Figure 4. The deposited Pt is clearly visible on the surface of the Si substrate, and layer thickness increases with additional ALD deposition cycles.

Comparison of the calculated film thicknesses obtained from the calibrated ALD growth rates and from XRF analysis can be seen in Table II. The XRF data shows good agreement with the ALD calculations, most notably for the $\mathrm{ZrO}_{2}$ and $\mathrm{ZnO}$ samples. In the $\mathrm{TiO}_{2}$ sample the layer thickness was so thin, and the emission intensity from $\mathrm{TiO}_{2}$ so low, that the calculated thickness was not reliable. The intensity for this thickness was about $0.08 \%$

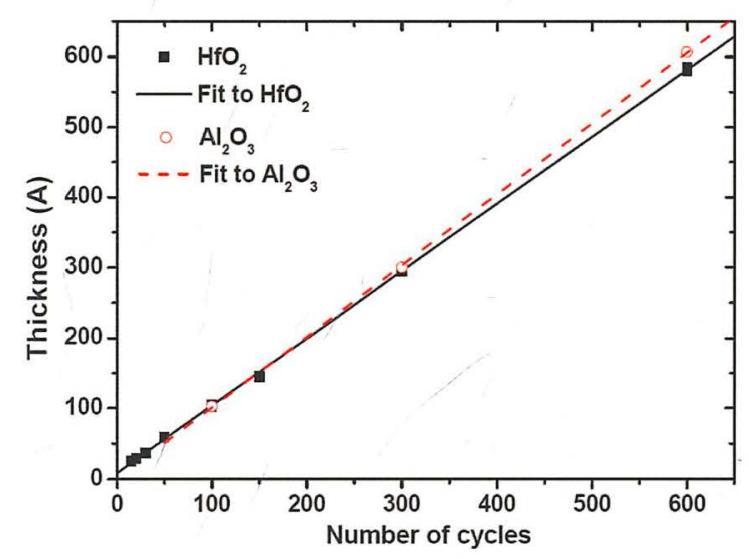

Figure 3. Linearity of $\mathrm{HfO}_{2}$ (black square) and $\mathrm{Al}_{2} \mathrm{O}_{3}$ (red circle) film thicknesses as measured via ellipsometry as a function of the number of ALD deposition cycles at $250{ }^{\circ} \mathrm{C}$. 


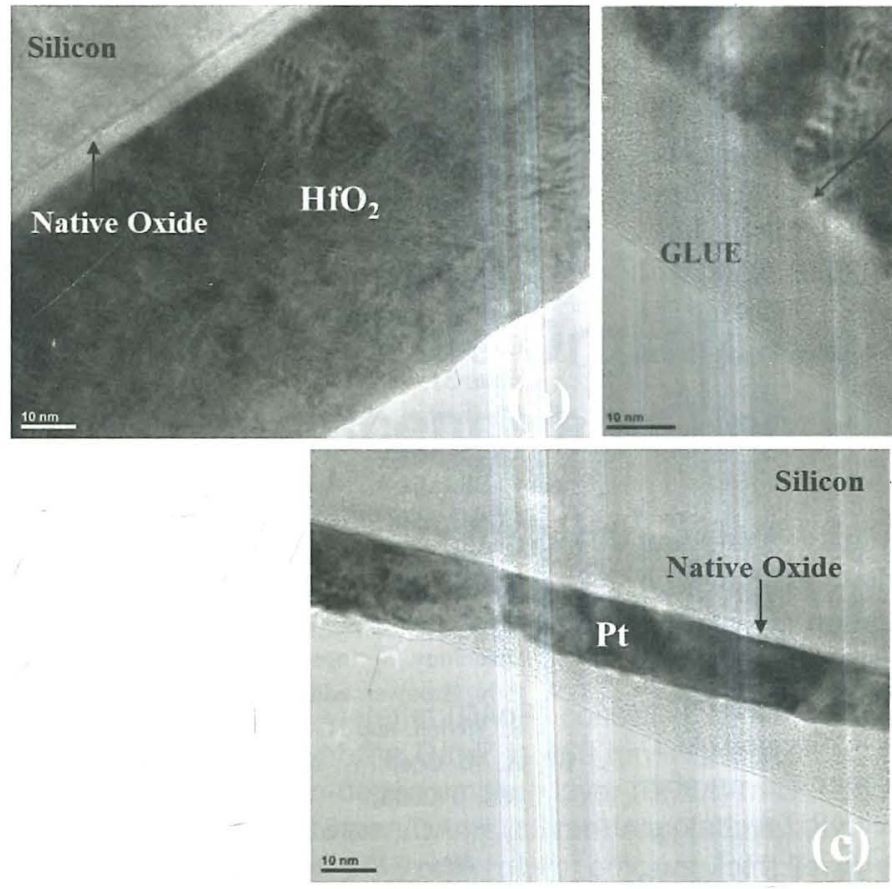

Figure 4. Example of cross-sectional TEM micrographs of ALD synthesized films utilized to measure the absolute film thickness (a) polycrystalline ALD $\mathrm{HfO}_{2}$ film annealed at $600{ }^{\circ} \mathrm{C}$ in $\mathrm{N}_{2}$ for $3 \mathrm{~min}$, (b) ALD ZnO films deposited at $150{ }^{\circ} \mathrm{C}$ and (c) ALD Pt film deposited with 200 ALD cycles.

of the intensity for an infinitely thick $\mathrm{TiO}_{2}$ sample. This explains the fairly large difference between the two XRFcalculated $\mathrm{TiO}_{2}$ thicknesses, with the absorption line calculated value of $19.2 \mathrm{~nm}$ the more reliable of the two numbers. For $\mathrm{HfO}_{2}$, the smaller difference is attributed to the diffusion layer formed between the $\mathrm{Hf}$ and the $\mathrm{Si}$ (Fig. 5) masking the signal emitted, thus causing an artificially lower calculated thickness for the absorption line. This formation of an interlayer has been observed in previous studies with the interlayer composition similar to hafnium-silicate, clearly differentiated from the Hf-O polycrystalline layer. ${ }^{18-20}$

Table II. Calculated thickness and area density of ALD thin film samples from ALD synthesis parameters and X-ray fluorescence spectroscopy analysis.

\begin{tabular}{|c|c|c|c|c|c|}
\hline \multirow{3}{*}{$\begin{array}{l}\text { Calculation } \\
\text { Method: } \\
\text { ALD } \\
\text { Sample }\end{array}$} & \multirow{3}{*}{$\begin{array}{c}\text { ALD growth } \\
\text { rate } \\
\begin{array}{c}\text { Thickness } \\
(\mathrm{nm})\end{array}\end{array}$} & \multicolumn{2}{|c|}{$\begin{array}{l}\text { XRF absorption } \\
\text { line }\end{array}$} & \multicolumn{2}{|c|}{$\begin{array}{c}\text { XRF emission } \\
\text { line }\end{array}$} \\
\hline & & \multirow[b]{2}{*}{$\begin{array}{c}\text { Thickness } \\
\text { (nm) }\end{array}$} & \multirow{2}{*}{$\begin{array}{c}\text { Area } \\
\text { density } \\
\left(\mu \mathrm{g} / \mathrm{cm}^{2}\right)\end{array}$} & \multirow[b]{2}{*}{$\begin{array}{c}\text { Thickness } \\
\text { (nm) }\end{array}$} & \multirow{2}{*}{$\begin{array}{c}\text { Area } \\
\text { density } \\
\left(\mu \mathrm{g} / \mathrm{cm}^{2}\right)\end{array}$} \\
\hline & & & & & \\
\hline $\mathrm{Al}_{2} \mathrm{O}_{3}$ & 30 & 22.9 & 9.14 & 22.5 & 9.0 \\
\hline $\mathrm{HfO}_{2}$ & 60 & 46.3 & 44.8 & 50.9 & 49.2 \\
\hline $\mathrm{TiO}_{2}$ & 21 & 19.2 & 8.14 & 10.1 & 4.28 \\
\hline $\mathrm{ZrO}_{2}$ & 20 & 19.8 & 11.2 & 16.6 & 9.43 \\
\hline $\mathrm{ZnO}$ & 1748 & 1710 & 965 & 1710 & 958 \\
\hline $\mathrm{Pt}$ & 20 & N/A* & N/A* & 23.6 & 50.4 \\
\hline
\end{tabular}

Note: *The high molecular weight of Pt prevented a sufficiently high reading for the absorption line from the underlying Si layer to be usable for calculation of the ALD layer thickness.
The strong agreement observed between the various techniques indicates that XRF is an excellent method for determination of layer thickness for these types of metal and transition metal oxide thin films, while retaining the key quality of being non-destructive..$^{2-4,8,10-14}$ Crosssectional evaluation methods such as TEM and SEM are destructive and for the case of X-TEM extremely time consuming, and cleavage of the films can actually disrupt measurements if softer metals like $\mathrm{Au}$ are contained in the deposited layer, in some cases preventing any kind of accurate measurement via this technique. ${ }^{17}$ ALD growth rate calculations can also be useful, though the time and expense of calibrating the method using ellipsometry and

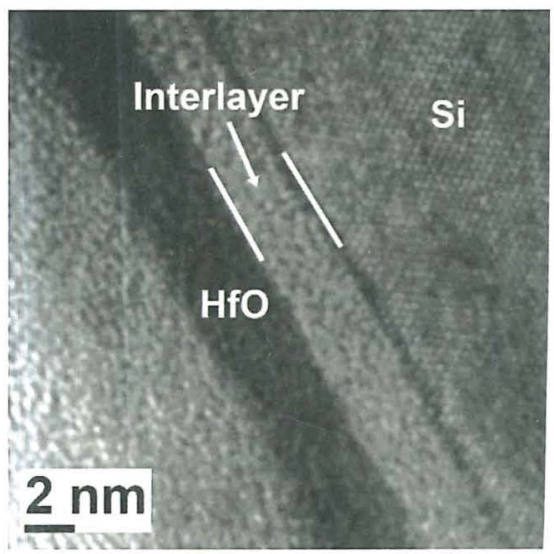

Figure 5. TEM cross-sectional image of an ALD thin film Hf-O sample on $\mathrm{Si}$, with a clearly visible interlayer. 
TEM and the multiple samples grown to different thicknesses is undesirable. XRF provides an accurate and far more rapid determination of layer thickness, while avoiding unnecessary production of excess test samples. This is in addition to being a non-destructive technique, allowing for further analysis of the same sample without damage from cross-sectional cleavage sites. Future work will involve the analysis of thin-film samples consisting of mixed-composition layers in addition to nanolaminate or superlattice structures via XRF.

\section{CONCLUSIONS}

This study demonstrated the use of XRF analysis utilizing comparatively the XRF absorption and the XRF emission line to determine the thickness of nanoscale $\mathrm{Al}_{2} \mathrm{O}_{3}, \mathrm{HfO}_{2}$, $\mathrm{Pt}, \mathrm{TiO}_{2}, \mathrm{ZnO}$, and $\mathrm{ZrO}_{2}$ thin films deposited on silicon substrates by ALD technology. The XRF thickness measurements agreed well with ellipsometry-calibrated ALD calculated values based on growth rate and the number of ALD deposition cycles, indicating the XRF technique was successful at accurately determining layer thickness. Due to the benefits of XRF analysis over alternative methods, including speed and the non-destructive nature of the technique, quantitative XRF spectroscopy has been shown to be a powerful non-destructive tool for thickness analysis of deposited ALD high- $k$ transition metal oxides and pure metal films. This technique has untapped application potential in integrated circuit fabrication and other technologically important nano-scaled thin films for microelectronics applications such as high- $k$ dielectric and metal gate stacks.

Acknowledgments: The authors gratefully acknowledge the financial support from NSF award No. 0959807.

\section{References and Notes}

1. C. Wyon, D. Delille, J. P. Gonchond, F. Heider, L. Kwakman, S. Marthon, I. Mazor, A. Michallet, D. Muyard, L. Perino-Gallice, J. C. Royer, and A. Tokar, Thin Solid Films 450, 84 (2004).

2. I. Queralt, J. Ibañez, E. Marguí, and J. Pujol, Spectrochim. Acta Part B At. Spectrosc. 65, 583 (2010).

3. M. Kolbe, B. Beckhoff, M. Krumrey, and G. Ulm, Spectrochim. Acta Part B At. Spectrosc. 60, 505 (2005).

4. C. Fiorini, A. Gianoncelli, A. Longoni, and F. Zaraga, X-ray Spectrom. 31, 92 (2002).

5. M. Barthel, V. Pedan, O. Hahn, M. Rothhardt, H. Bresch, O. Jann, and S. Seeger, Environ. Sci. Technol. 45, 7819 (2011).

6. F. Blockhuys, M. Claes, R. Van Grieken, and H. J. Geise, Anal. Chem. 72, 3366 (2000).

7. S. Peng, Z. Liu, T. Sun, G. Wang, Y. Ma, and X. Ding, Appl. Radiat. Isot. 90,84 (2014).

8. M. S. Shackley, X-ray Fluorescence Spectrometry (XRF) in Geoarchaeology, Springer New York, New York, NY (2011).

9. P. N. Brouwer, edited by B. Beckhoff, B. Kanngie $\beta$ er, R. Langhoff, R. Wedell, and H. Wolff, Springer, Berlin (2006), Chap. 5, p. 863.

10. Z. W. Chen, W. M. Gibson, and H. Huang, X-ray Opt. Instrum. 488, 1 (2008).

11. J. A. M. Vrielink, R. M. Tiggelaar, J. G. E. Gardeniers, and L. Lefferts, Thin Solid Films 520, 1740 (2012).

12. P. Van Dyck and R. Van Grieken, Anal. Chem. 52, 1859 (1980).

13. K. Nielson, Anal. Chem. 49, 641 (1977).

14. D. Laguitton and W. Parrish, Anal. Chem. 49, 1152 (1977).

15. J. Sherman, Spectrochim. Acta 7, 283 (1955).

16. M. H. J. Bekkers and H. A. Van Sprang, X-ray Spectrom. 26, 122. (1997).

17. J. A. M. Vrielink, R. M. Tiggelaar, J. G. E. Gardeniers, and L. Lefferts, Thin Solid Films 520, 1740 (2012).

18. S. C. Chen, J. C. Lou, C. H. Chien, P. T. Liu, and T. C. Chang, Thin Solid Films 488, 167 (2005).

19. R. Puthenkovilakam, Y.-S. Lin, J. Choi, J. Lu, H.-O. Blom, P. Pianetta, D. Devine, M. Sendler, and J. P. Chang, J. Appl. Phys. 97, 023704 (2005).

20. D. Gu, H. Baumgart, T. M. Abdel-Fattah, and G. Namkoong, ACS Nano 4, 753 (2010).

Received: 11 March 2016. Accepted: 3 August 2016. 